\title{
ANALYSIS OF RIGID AND FLEXIBLE DYNAMICS OF A SPACE-SLIDER- CRANK MECHANISM BASED ON FINITE ELEMENT METHOD
}

\author{
NGOC THAI HUYNH, CONG RO HOANG, TRUNG KIEN TRAN, VAN HOAI LE \\ Faculty of Automtive Engineering Technology, Industrial University of Ho Chi Minh City \\ huynhngocthai@iuh.edu.vn
}

\begin{abstract}
The investigation analyzes effects of clearance size in revolute and spherical joints with clearance on rigid-flexible dynamic of a space slider crank mechanism by finite element method. The model of the mechanism was designed by Solidworks and then velocity, acceleration, displacement, stress and contact force were determined by finite element analysis of rigid-transient dynamic in ANSYS. The results simulation indicated that the clearance size in revolute and spherical with clearance has sightly effected on the velocity of the slider, but has significantly effected on acceleration, contact force as journal and ball impact into bearing and socket with high peaks of acceleration and contact force as presented in the graph of acceleration and contact forces. The graph outlined that journal and ball motion with three types: free light, contact and impact motion. Clearance size created deviation for the displacement of the slider from $4.29 \mathrm{~mm}$ to $9.87 \mathrm{~mm}$ and maximum principal stress increases from 8.4 MPa to $10 \mathrm{MPa}$ when clearance size increases from $0 \mathrm{~mm}$ to $0.3 \mathrm{~mm}$.
\end{abstract}

Keywords. Space slider crank mechanism, finite element method, rigid-flexible dynamic, revolute clearance joint, spherical clearance joint.

\section{INTRODUCTION}

The slider crank mechanism was widely used in the field of engineering and life. The machine system is operated thanks to the connection between the links by joints. A clearance size and friction are also exist in a real joint. The clearance joint helps links motion easily. However, clearance size and the number of clearance joint increases, contact force and acceleration increase [1-3] causes vibration, noisy and wear due to collision. In order to reduce wear, Jorge Ambrósio and Paulo Verissimo [4] proposed bushing model for spherical, revolute and translation joint in vehicle suspensions. The results of analysis demonstrated that bushing model for mechanical joints are better than only use mechanical joints. Besides, Paulo Flores and HamidM. Lankarani [5] applied lubricated model in spherical joint with clearance to decrease wear. The results outlined the lubricated model created contact force peaks lower than dry contact model in computation dynamic of four bar mechanisms. Enlai Zheng et al [6] analyzed dynamic responses of ultra-precision presses with flexible multi-link, spherical clearance joint, revolute clearance joint and lubricated joint. The result of the analysis of lubricated clearance joint model agree better than dry contact condition and type of motion of journal and ball is free light motion and impact motion. In order to reduce effects of clearance in classical joint, Selçuk Erkaya et al [7] utilized pseudorigid-body model which reduces the chaotic vibration increasing from revolute gap joints. An elastohydrodynamic lubricated model of spherical clearance joint for dynamics of multibody with flexible is outlined by Qiang Tian et al [8]. The simulation results were confirmed by software ADINA. Gengxiang Wang and Liang Wang [9] used the Lankarani-Nikravesh contacts force model and a modified Coulomb friction mode to estimate contact force in spherical joint with clearance of spatially parallel mechanism considering rod flexibility. Ehsan Askari and Paulo Flores [10] utilized fluid dynamics and Coupling model to lubricate for spherical joint. The proposed model is a robust dynamic model that provides promising results and can be used to study hydrodynamic lubrication of both biomedical joints, e.g. hip prostheses, and industrial spherical joints. The effect of clearance size and friction coefficient on the space robot manipulator was modeled, analyzed and quantified by Wuweikai Xianga et al $[11,12]$ based on Chebyshev polynomials method. The analysis of results demonstrated that clearance size and friction coefficient have significantly affected the behaviour dynamic of the space robot manipulator. The non-linear analysis to determine chaotic response of moving mechanism with clearance joint was performed by Qingfeng Xiao et al [13]. The outline of analysis pointed out the 
clearance size increases or the number of clearance fault increase, the acceleration will oscillate more violent and have higher amplitude., Furthermore, it is more possible to show chaotic behaviors.

The previous study only analyzed behaviour dynamic of phanar multibody mechanical systems. In this investigation, the analysis of effects of clearance and friction on rigid-flexible dynamic of space slidercrank mechanism based on finite element method in ANSYS is a novel in this investigation.

\section{SPACE SLIDER-CRANK MECHANISM}

\subsection{Design a space-slider-crank mechanism}

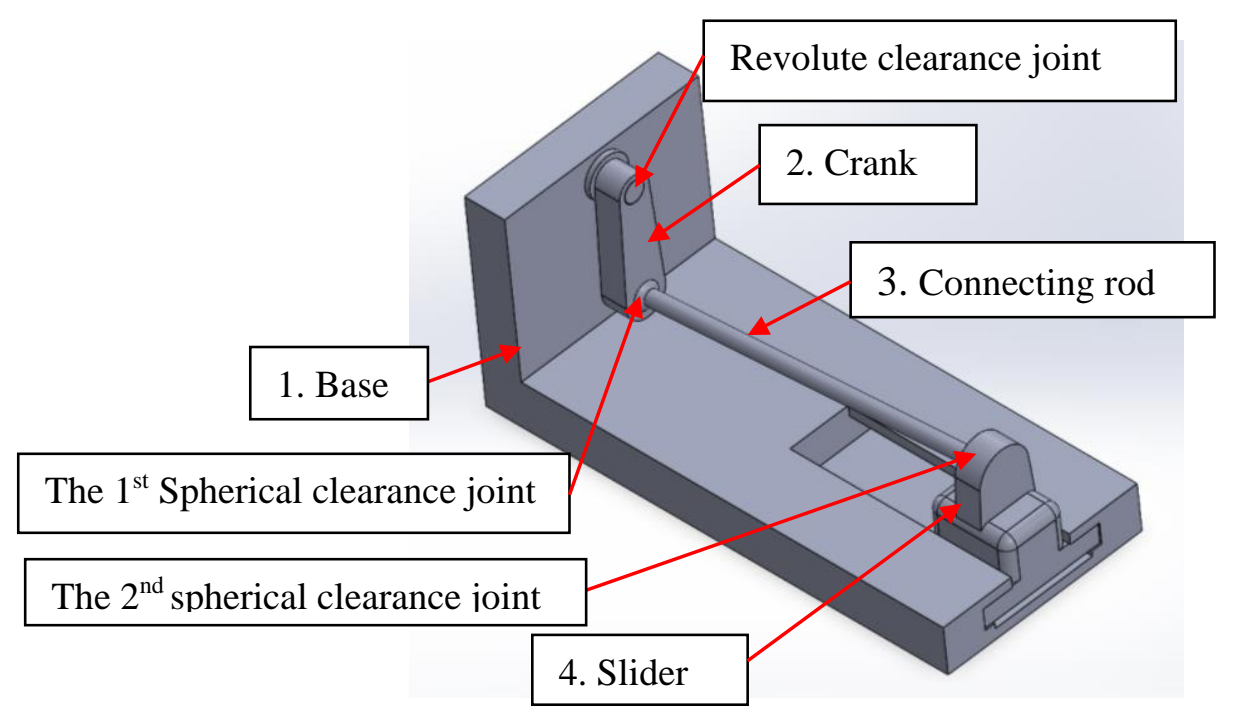

\section{Figure 1: Space Slider-crank mechanism with revolute and spherical clearance joints}

The mechanism was used in industry and life, was designed by Solidworks as presented in Figure 1 consist of Base, crank, connecting rod and slider. The velocity and acceleration of slider and contact force in revolute clearance joint and two spherical joints were obtained by rigid-transient in ANSYS. The dimension of the model as depicted in Table 1

Table 1 Simulation characteristics

\begin{tabular}{lc}
\hline Parameters & Value \\
\hline Length of crank $(\mathrm{mm})$ & 100 \\
Mass of crank $(\mathrm{kg})$ & 0.723 \\
Length of connecting rod $(\mathrm{mm})$ & 380 \\
Mass of connecting rod $(\mathrm{kg})$ & 0.605 \\
Mass of slider $(\mathrm{kg})$ & 3.37 \\
\hline
\end{tabular}

\subsection{Model of the revolute clearance joint}

In revolute ideal joint center of journal and bearing is coincident, but in revolute clearance joint the center of their different. The clearance always absent in revolute joint is due to tolerance manufacture, assembly, wear which it allows motion between two body. The base and crank are connected by revolute clearance joint as depicted in Figure 2. Dynamic of this joint is due to journal impact into bearing causes collision between the journal and bearing in dry contact condition.

$$
c=r_{B}-r_{j}
$$

where $r_{B}, r_{j}$ are the radii of the bearing and the journal, and $l_{\mathrm{B}}$ and $d_{\mathrm{B}}$, are the length of bearing and diameter of the bearing, respectively. 


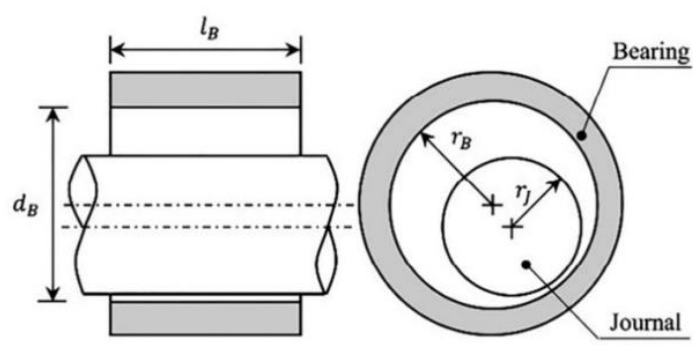

\subsection{Model of spherical clearance joint}

Figure 2: Revolute clearance joint model

Similarly, clearance is also existed in a practical spherical joint which is difference between a radius of ball and radius of socket. The model of a spherical clearance joint as outlined in Figure 3 is used to connect between crank and connecting rod, between the connecting rod and the slider.

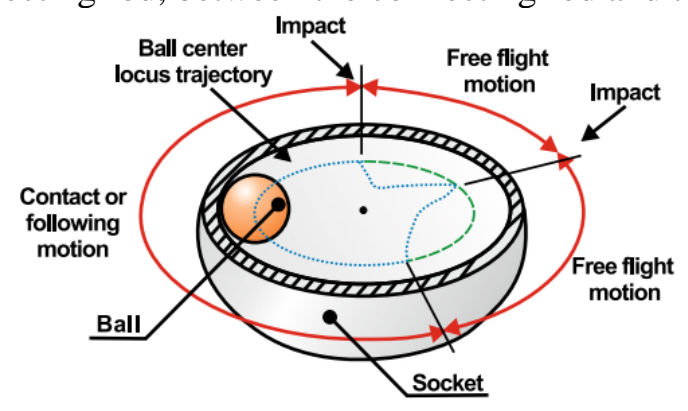

\subsection{Finite element analysis}

\section{Figure 3: Spherical clearance joint model}

The connecting rod was set flexible, the ball is flexible, the socket is rigid. The material property of base, crank, connecting rod and slider is structural steel with Modulus of elasticity is $200 \mathrm{GPa}$, Poisson's ratio is 0.3 , density is $7850 \mathrm{~kg} / \mathrm{m}^{3}$. The model was meshed by automotive with 22749 triangle elements and 41481 nodes. The boundary condition was set up as illustrated in Figure 2 consist of fix joint, revolute clearance joint, two spherical joints with clearance, translation joint and joint load with iput velocity $300 \mathrm{rpm}$.

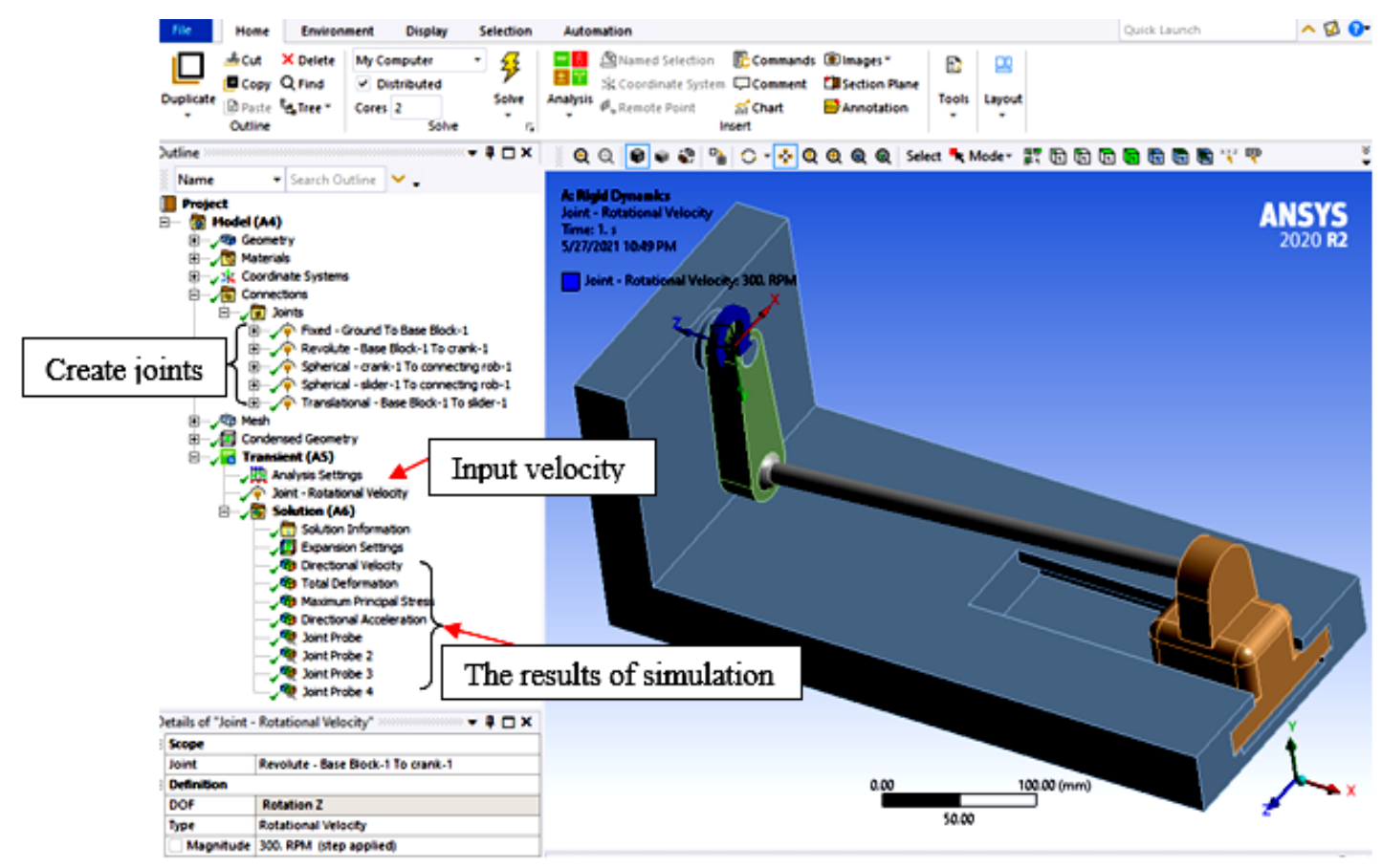

Figure 4: Set up boundary condition for model in ANSYS 


\section{RESULTS AND DISCUSSIONS}

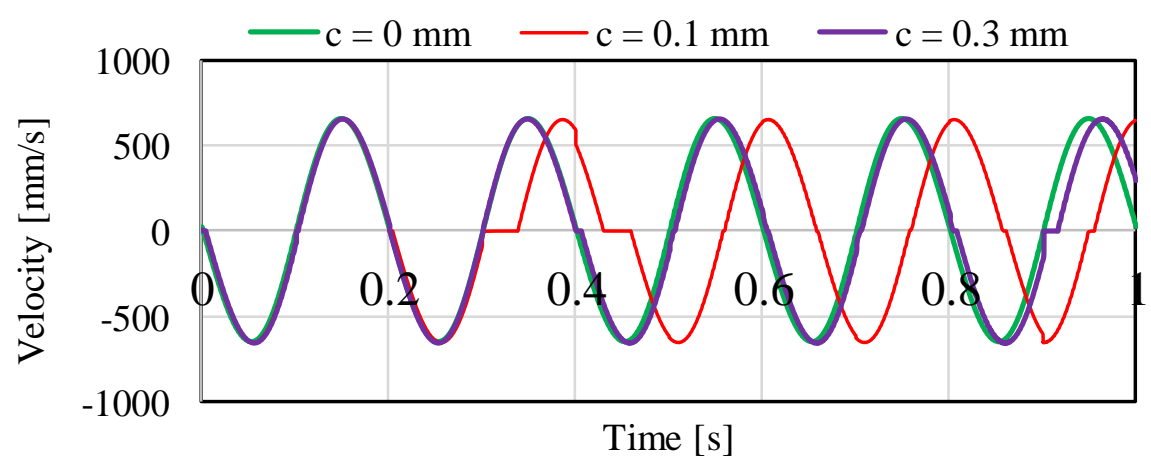

Figure 5: The velocity of slider

The initial the crank lies a straight line $y$-axis direction with time step is $0.001 \mathrm{~s}$, input driven speed is 300 rpm put on in revolute clearance joint link between crank and base. In this investigation assumed that the ball rolls in socket of spherical clearance joint with 0.01 coefficient friction and journal rolls in bearing of revolute clearance joint with 0.08 coefficient friction, respectively. The slider slides on the base with 0.2 coefficient friction in the translation joint. The simulation was performed with assuming different clearance size $(c) 0 \mathrm{~mm}, 0.1 \mathrm{~mm}$ and $0.3 \mathrm{~mm}$. The center of the socket and ball deviation is equal to clearance size in dry contact condition. The FEM result indicated that velocity of slider insignificant change when c increases from $0 \mathrm{~mm}$ to $0.3 \mathrm{~mm}$ as pointed out in Figure 5 . The clearance size is equal to 0 $\mathrm{mm}, 0.1 \mathrm{~mm}$ and $0.3 \mathrm{~mm}$, the maximum value of velocity of slider is $654.05 \mathrm{~mm} / \mathrm{s}, 655.4 \mathrm{~mm} / \mathrm{s}$ and $657.81 \mathrm{~mm} / \mathrm{s}$, respectively. However, the acceleration of slider is oscillated chaotic by $c$ and increased when $c$ increases from $0 \mathrm{~mm}$ to $0.3 \mathrm{~mm}$ as shown in Figure 6 . The clearance size is equal to $0 \mathrm{~mm}, 0.1$ $\mathrm{mm}$ and $0.3 \mathrm{~mm}$, the maximum value of acceleration of slider is $60960 \mathrm{~mm} / \mathrm{s}^{2}, 63655 \mathrm{~mm} / \mathrm{s}^{2}$ and 69616 $\mathrm{mm} / \mathrm{s}^{2}$. The acceleration increases as clearance size increases.

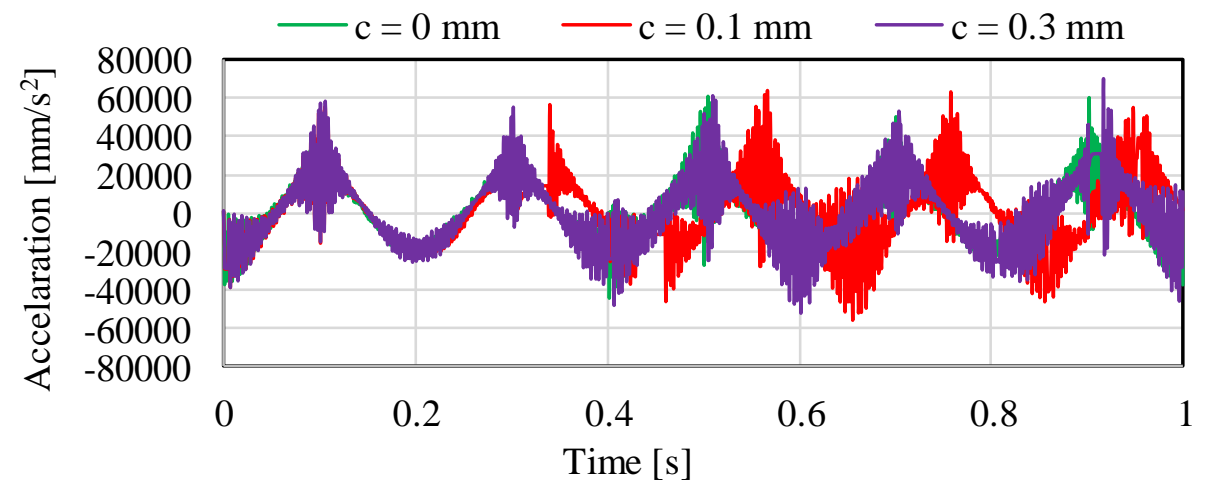

Figure 6: The aceleration of slider

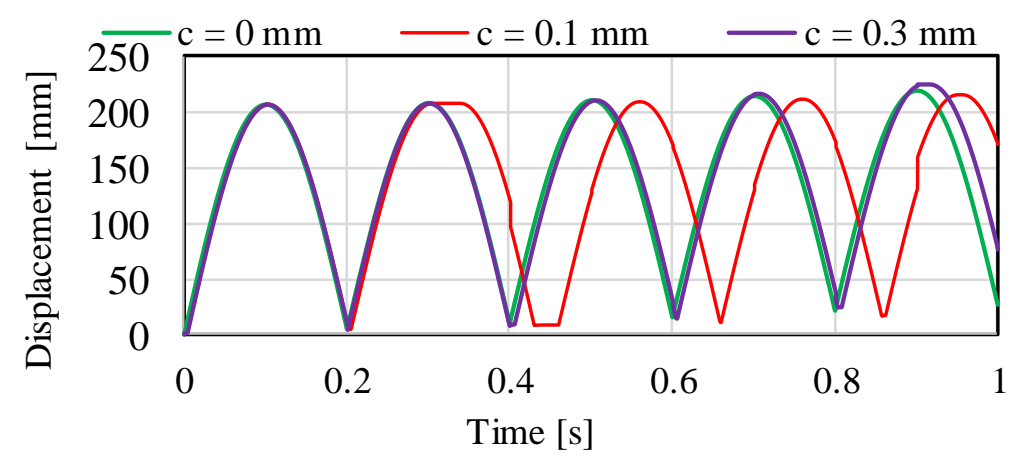

Figure 7 The displacement of slider 
The graph of the displacement of slider as pointed out in Figure 7 is chaotic vibration. The problem indicated that the displacement of the slider is significantly affected by clearance size and friction in revolute and spherical clearance joints. And the displacement of slider has deviation due to $c$ increases from $0 \mathrm{~mm}$ to $0.3 \mathrm{~mm}$. The maximum value of deviation is $4.29 \mathrm{~mm}$ when clearance size is equal to 0.1 $\mathrm{mm}$ and $9.87 \mathrm{~mm}$ when clearance size is equal to $0.3 \mathrm{~mm}$.

The graph of the maximum principal stress of the connecting rod as presented in Figure 8 was significantly vibrated by clearance size, friction and input velocity. Because the $c$ increases from $0 \mathrm{~mm}$, $0.1 \mathrm{~mm}$ to $0.3 \mathrm{~mm}$ and input velocity is $300 \mathrm{rpm}$ causes the maximum principal stress of the connecting rod increases from 8.4 MPa, 8.78 MPa to10 $\mathrm{MPa}$, respectively. The problem proved that clearance size increases, the stress significantly increases. In order to the mechanical systems operates well the stress reduces and thereby clearance size decreases.

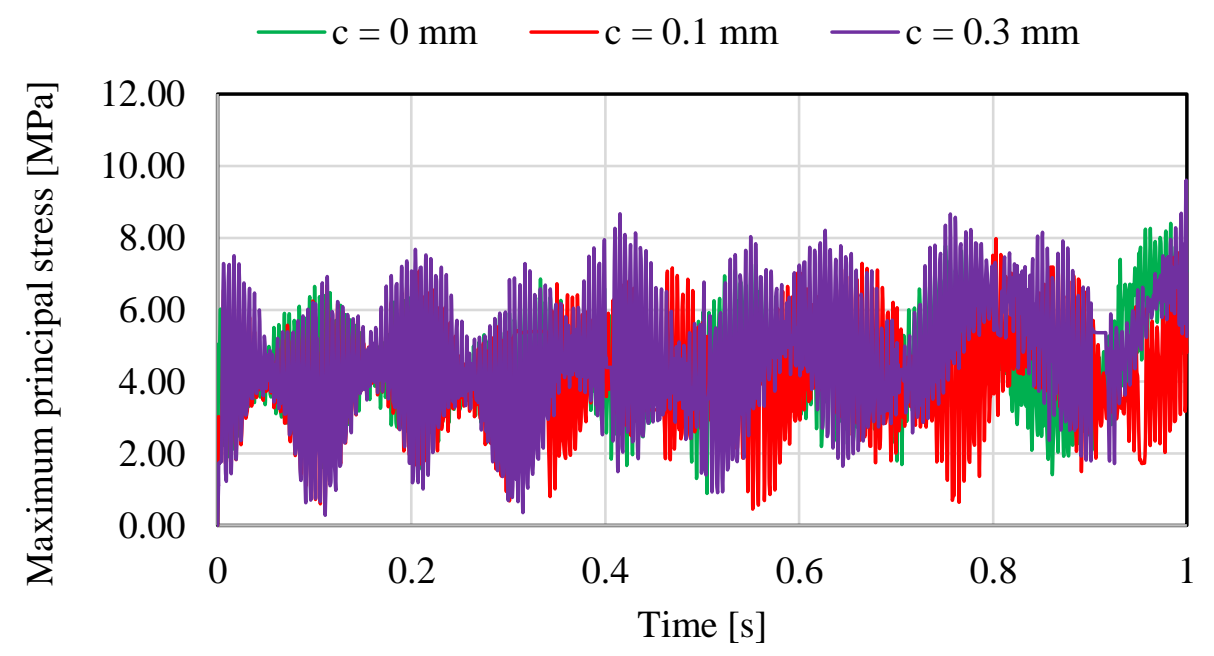

Figure 8 The stress of connecting rod

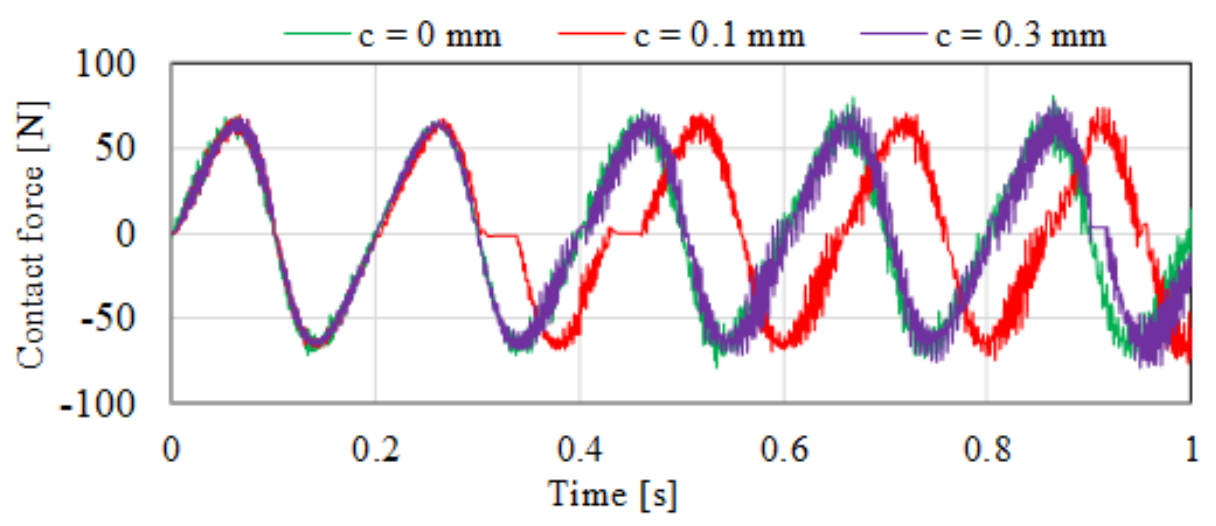

Figure 9 The contact force of Axis $X$ direction of revolute clearance joint

The contact forces in revolute clearance joint according to $\mathrm{x}$-axis direction as outlined in Figure 9 is vibrated chaotic by $c$ and increases when $c$ increases from $0 \mathrm{~mm}$ to $0.3 \mathrm{~mm}$ and input velocity is $300 \mathrm{rpm}$. The peaks of contact force are due to journal impact into bearing causes. The graph indicated that motion of journal consists of three types motion: free motion, contact motion, impact motion. These phenomena are also presented in [7, 12-14]. 


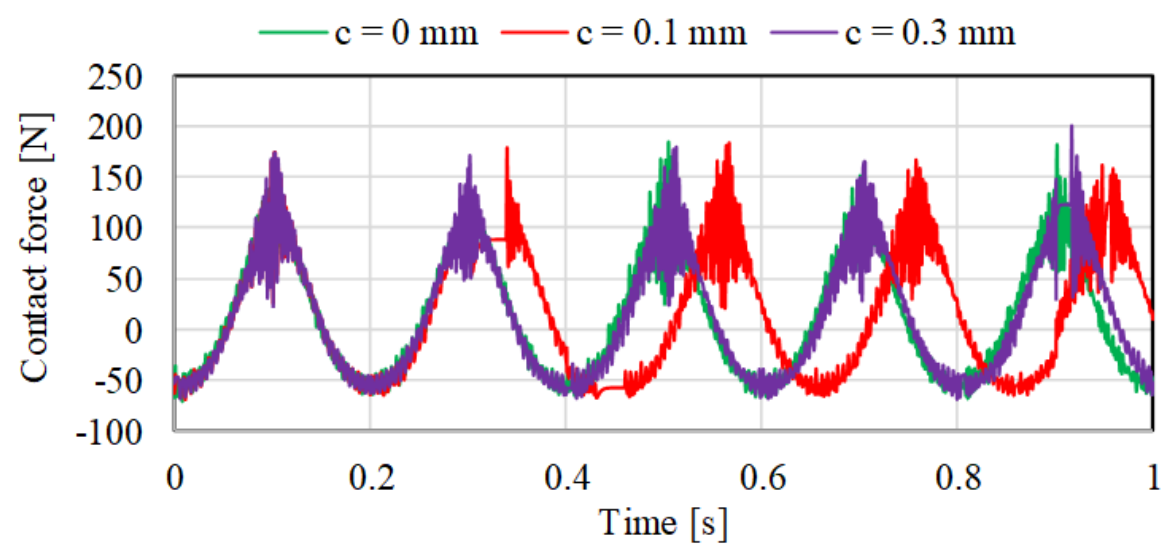

Figure 10 The contact force of Axis $Y$ direction of revolute clearance joint

The graph of the contact forces in revolute clearance joint according to y-axis direction as illustrated in Figure 10 is significantly oscillated $c$ increases from $0 \mathrm{~mm}$ to $0.3 \mathrm{~mm}$ and driven speed is $300 \mathrm{rpm}$. When the journal impact into bearing causes the high peaks contact force. The graph indicated that if clearance size contine to increases, the vibration of space silder-crank mechanism increases and the noise can not avoid due to impact. And to the finally the revolute will wear quickly. These phenomena are also outlined in $[7,12-14]$.

A testament for the contact forces according to z-axis direction in revolute clearance joint is pointed outed in Figure. 11. The graph described instability when $c$ increases from $0 \mathrm{~mm}$ to $0.3 \mathrm{~mm}$ with the high peaks of the contact force. The force peaks are due to journal impact into bearing. The phenomena are also described in [7, 12-14].

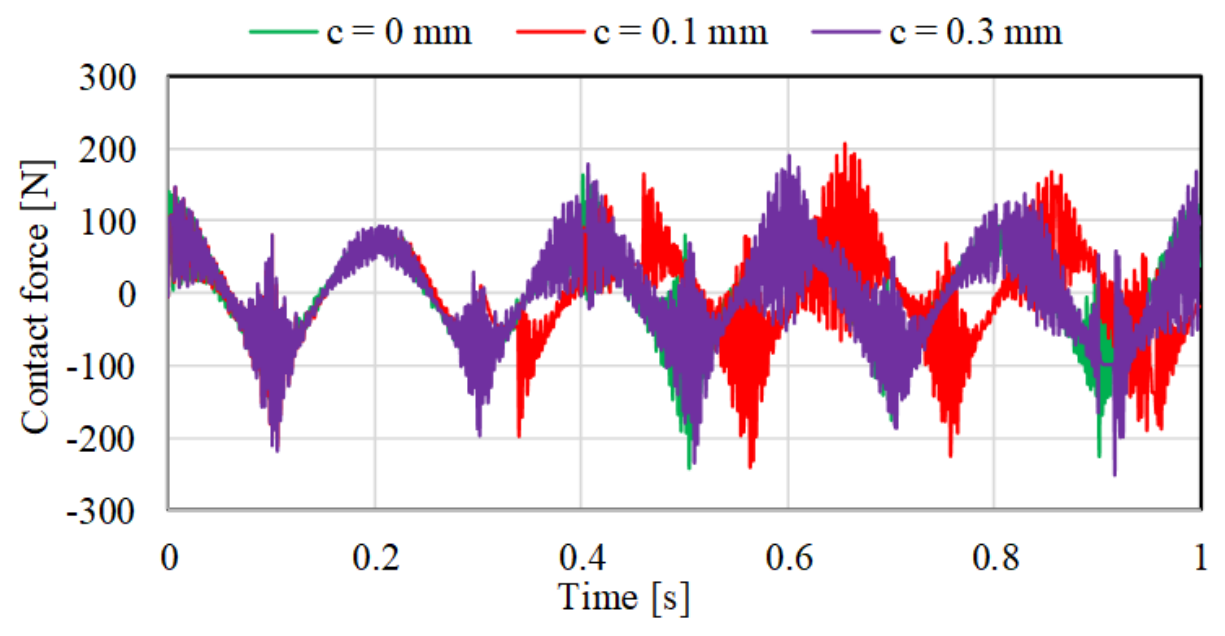

Figure 11 The contact force of Axis $Z$ direction of revolute clearance joint

Similarly, the graph of the contact forces in the first spherical clearance joint according $x$-axis direction as Figures 12 is vibrated chaotic with high peaks of the contact forces take place suddenly as ball bump into the socket. The graph identified that ball motion with three types: free light motion, contact motion and impact motion and these problems are also stated in [7, 12-14]. 


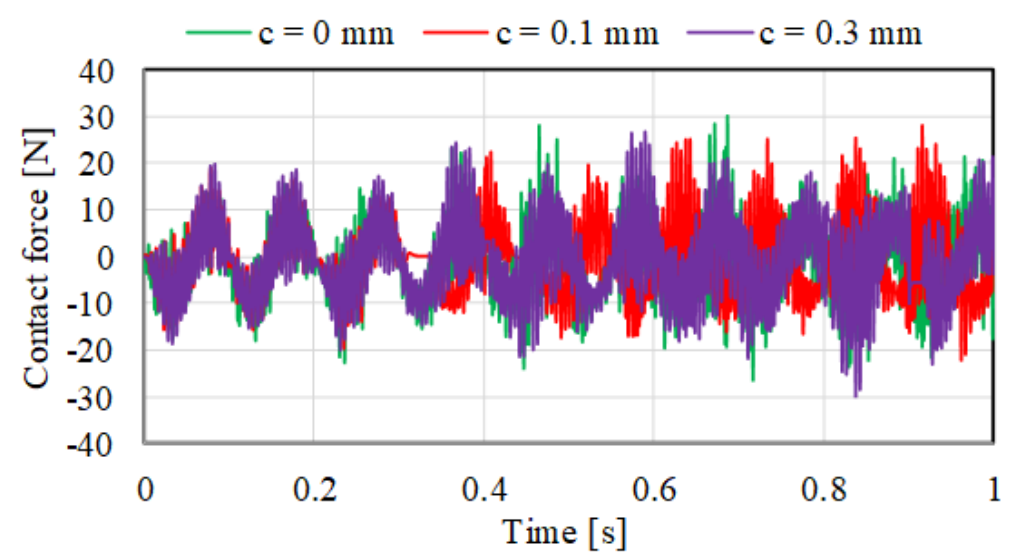

Figure 12 The contact force of Axis $X$ direction of the $1^{\text {st }}$ spherical clearance joint

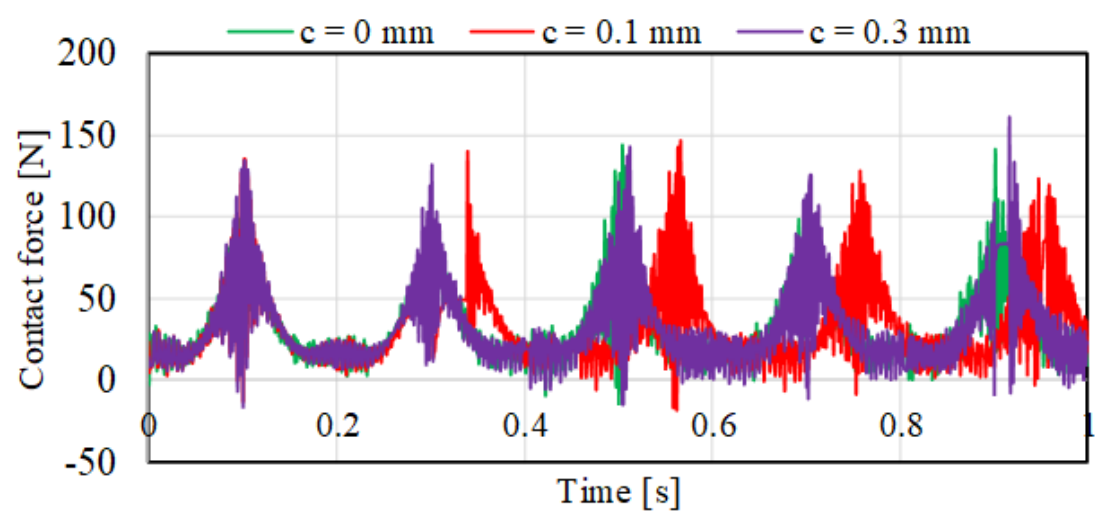

Figure 13 The contact force of Axis $Y$ direction of the $1^{\text {st }}$ spherical clearance joint

Likes the contact force according $\mathrm{x}$-axis direction, the graph of the contact forces in the first spherical clearance joints according $\mathrm{y}$-axis direction as depicted in Figures 13 is oscillated stronger than the contact force according $\mathrm{x}$-axis direction with force peaks are higher $150 \mathrm{~N}$. While the contact force according $\mathrm{x}$ axis direction in the $1^{\text {st }}$ spherical is $30 \mathrm{~N}$. and the quantity of high peaks of the contact force according $\mathrm{y}$ axis direction are less than according $\mathrm{x}$-axis direction. These phenomena of the oscillation were pointed out in [7, 12-14]

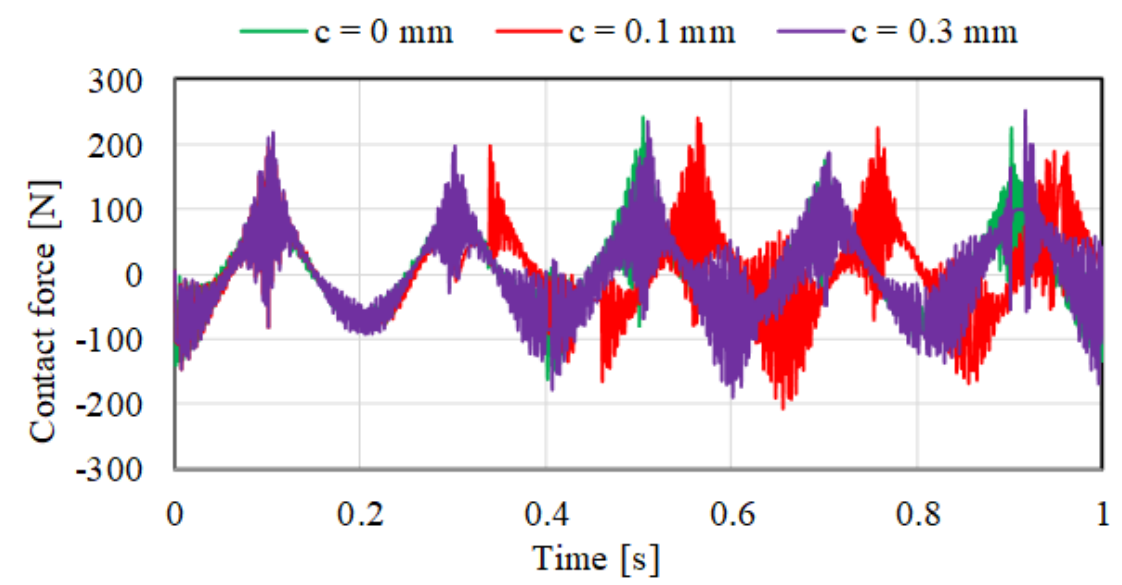

Figure 14 The contact force of Axis $Z$ direction of the $1^{\text {st }}$ spherical clearance joint 
The graph of the contact forces in the first spherical clearance joints according $z$-axis direction as drawn out in Figure 14 is oscillated with high peaks $200 N$ likes the contact force in the first spherical clearance joints according $x$-axis direction. The number of high peaks of contact force according $z$-axis direction is less than according $z$-axis direction and is equal to according $y$-axis direction. These phenomena of oscillation were proved in [7, 12-14]. Figures 15 is the plot of the contact forces in the second spherical clearance joints according $x$-axis direction. The graph outlined that clearance size made the contact force strongly increases with high peaks. The value of the contact force obtained $40 \mathrm{~N}$ and the quantity of peaks is 10 . The vibration increases when clearance size increase from $0 \mathrm{~mm}$ to $0.3 \mathrm{~mm}$. These problems were also analyzed in [7, 12-14]. The graph of the contact forces in the second spherical clearance joints according $y$-axis direction Figures 16. The number of the high peaks of the contact force is less than according $x$-axis direction, but the values of the contact force is $100 \mathrm{~N}$. These problems are also demonstrated in [7, 12-14]. In the Figure 16 indicated that the graph of the contact forces in the second spherical clearance joints according $z$-axis direction is vibrated chaotic with high peaks by clearance size. The quantity of the high peaks of the contact force is 5 , the value of the contact force is over $200 \mathrm{~N}$. The phenomena increasing of the contact force is due to clearance size increases, was pointed out in [7, 1214].

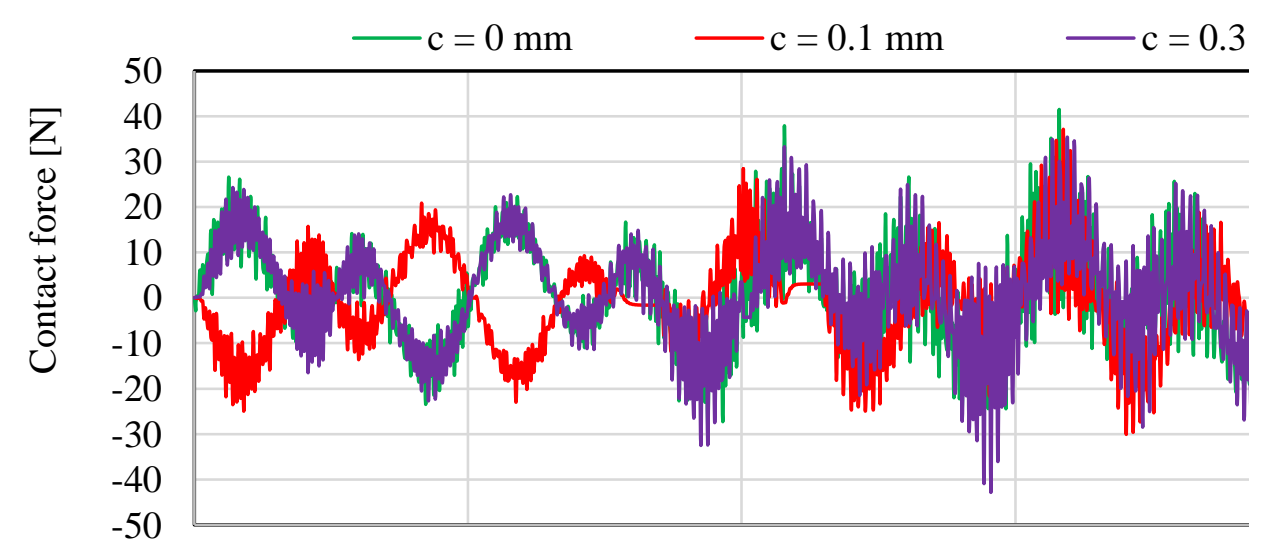

Figure 15 The contact force of Axis X direction of the $2^{n}$ spherical clearance joint

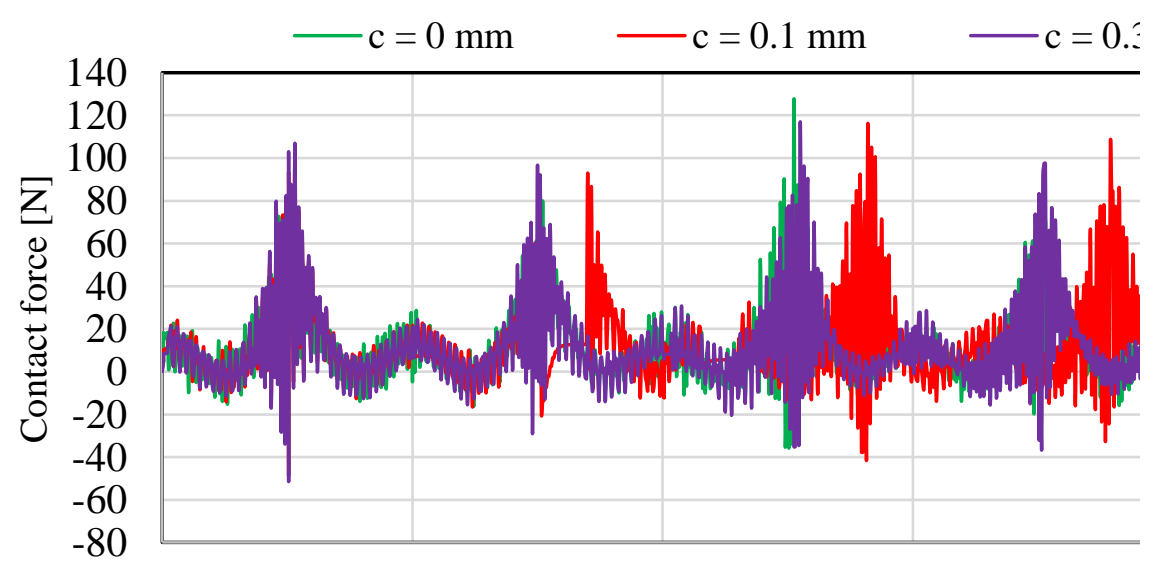

Figure 16 The contact force of Axis $Y$ direction of the $2^{\text {nd }}$ spherical clearance joint 


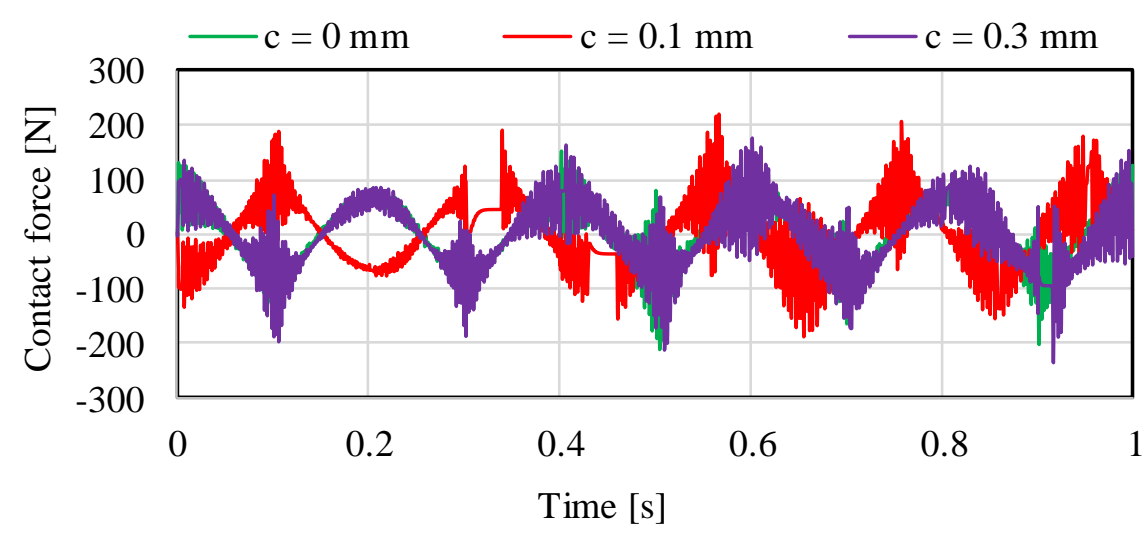

Figure 17 The contact force of Axis $Z$ direction of the $2^{\text {nd }}$ spherical clearance joint

The same as the contact force in revolute and spherical joint according to $\mathrm{x}, \mathrm{y}, \mathrm{z}$ axis direction, The graph of the contact force in translation joint according to $x$-axis direction as presented in Figure 18 is unstable due to impact between journal and bearing in revolute clearance joint and impact between ball and socket in spherical clearance joint. Due to this problem which the acceleration of slider is unstable with high peaks. The maximum value of the contact force in translation joint achieved approximately $100 \mathrm{~N}$. These phenomena of oscillation is similar to these explanations in $[7,12-14]$.

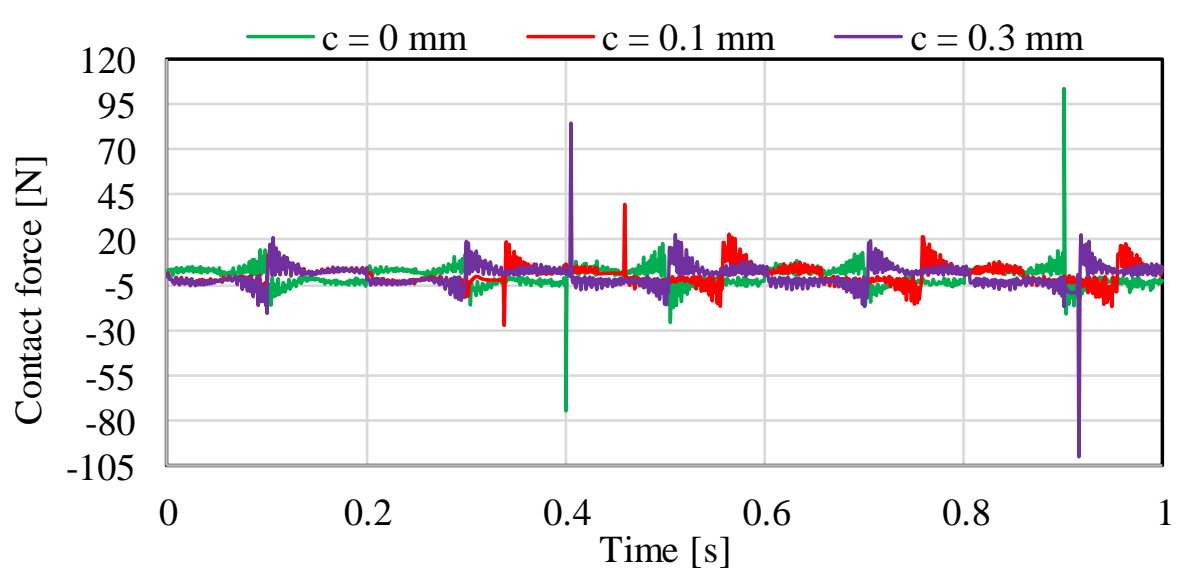

Figure 18 The contact force of Axis $X$ direction of translation joint without clearance

As shown in Figure 19, The graph of the contact force in translation joint according to $y$-axis direction have many high peaks takes place suddenly due to journal and ball impact into bearing and socket. The vibration increase when $c$ increases from $0 \mathrm{~mm}$ to $0.3 \mathrm{~mm}$ and obtained over $120 \mathrm{~N}$. the problem contributed to increasing instability of the slider as illustrated in [7, 12-14].

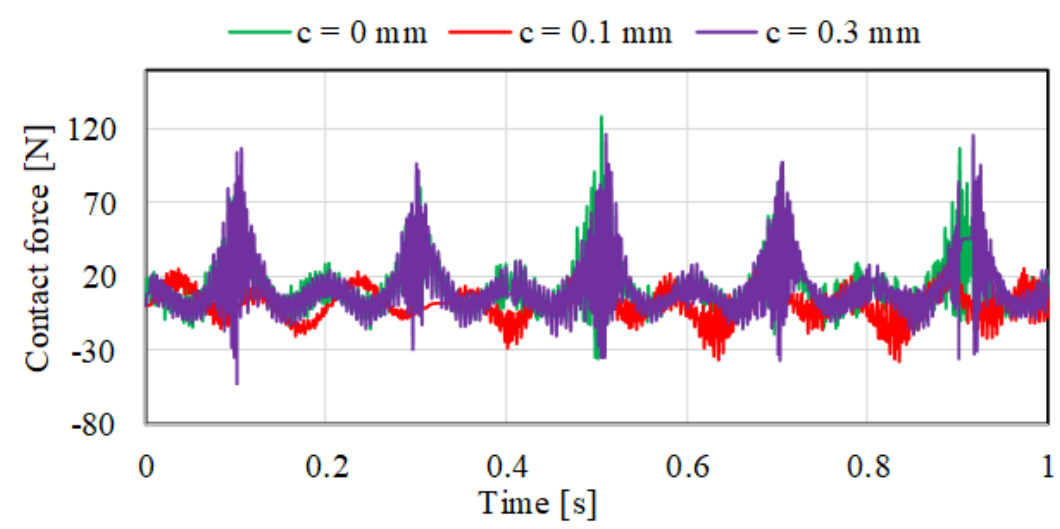

Figure 19 The contact force of Axis $Y$ direction of translation joint without clearance 


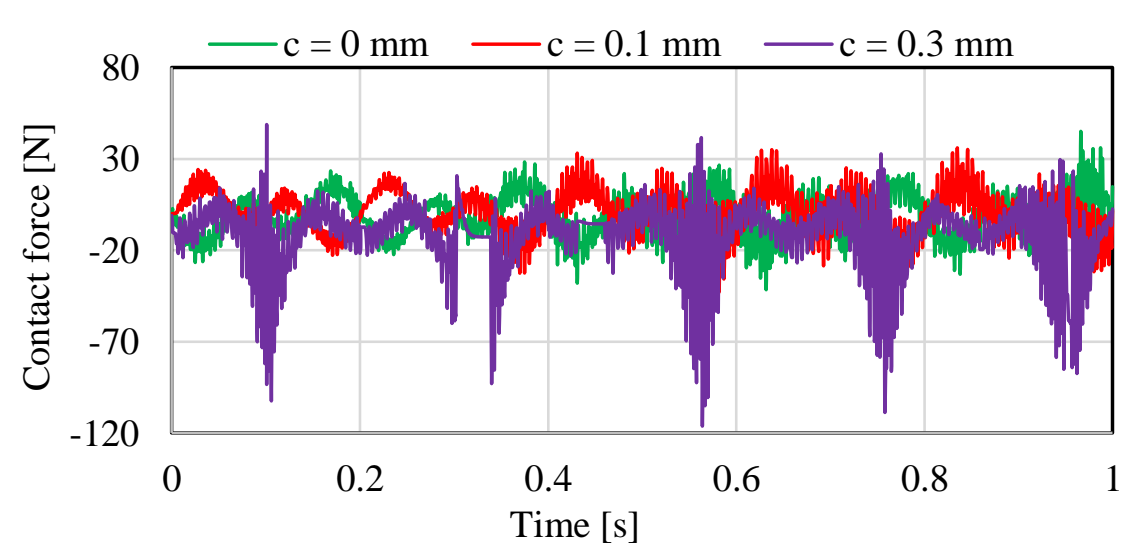

Figure 20 The contact force of Axis $Z$ direction of translation joint without clearance

And finally, The graph of the contact force in translation joint according to $z$-axis direction as depicted in Figure 20 is over $120 \mathrm{~N}$. The plot pointed out many maximum value. This problem make to increase chaotic oscillation of the mechanical system as outlined in [7, 12-14].

\section{CONCLUSION}

The study investigated analysis of dynamic of rigid and flexible of space slider crank mechanism with revolute clearance joint and two spherical joints with clearance by finite element method in ANSYS. The result of the simulation indicated that velocity of slider is insignificant effected by clearance. But acceleration and contact force in revolute and spherical joint with clearance is significant vibrated chaotic with high peaks are due to journal crashed into bearing, ball bump into socket, motion of journal and ball are free light motion, contact motion and impact motion. The displacement of slider has significantly changed as clearance size increases from $0 \mathrm{~mm}$ to $0.3 \mathrm{~mm}$. The problem identified that connecting rod has deformation and maximum principal stress of the connecting rod is $10 \mathrm{MPa}$ at $\mathrm{c}$ is $0.3 \mathrm{~mm}$. The outcomes can apply for analysis response dynamic of multi-body mechanisms with spherical and revolute clearance joints such as analysis dynamic of steering system in a car, dynamic of space robot. The clearance size is zero, the connected links move very difficult because have high friction, the clearance size is 0.3 the connected links move so easy. But the ball impacted into socket and journal impacted into bearing cause unstable vibration for the mechanical system. The clearance size is 0.1 the operation of space slider crank mechanism is better.

\section{References}

[1] N.-T. Huynh, S.-C. Huang, and T.-P. Dao, "Effects of material characteristics and clearance size on dynamics of a slider-crank mechanism with two sliders and revolute clearance joints," IOP Conference Series: Materials Science and Engineering, vol. 378, p. 012016, 2018.

[2] N.-T. Huynh, S.-C. Huang, and T.-P. Dao, "Analysis influence of journal radius and length of bearing on dynamics of a slider-crank mechanism with two sliders and revolute clearance joints," Journal of Physics: Conference Series, vol. 1074, p. 012005, 2018.

[3] N.-T. Huynh, S.-C. Huang, and T.-P. Dao, "Design variables optimization effects on acceleration and contact force of the double sliders-crank mechanism having multiple revolute clearance joints by use of the Taguchi method based on a grey relational analysis," Sādhanā, vol. 45, 2020.

[4] J. Ambrósio and P. Verissimo, "Improved bushing models for general multibody systems and vehicle dynamics," Multibody System Dynamics, vol. 22, pp. 341-365, 2009.

[5] P. Flores and H. M. Lankarani, "Spatial rigid-multibody systems with lubricated spherical clearance joints: modeling and simulation," Nonlinear Dynamics, vol. 60, pp. 99-114, 2009.

[6] E. Zheng, T. Wang, J. Guo, Y. Zhu, X. Lin, Y. Wang, et al., "Dynamic modeling and error analysis of planar flexible multilink mechanism with clearance and spindle-bearing structure," Mechanism and Machine Theory, vol. 131, pp. 234-260, 2019.

[7] S. Erkaya, S. Doğan, and E. Şefkatlığlu, "Analysis of the joint clearance effects on a compliant spatial mechanism," Mechanism and Machine Theory, vol. 104, pp. 255-273, 2016. 
[8] Q. Tian, J. Lou, and A. Mikkola, "A new elastohydrodynamic lubricated spherical joint model for rigid-flexible multibody dynamics," Mechanism and Machine Theory, vol. 107, pp. 210-228, 2017.

[9] G. Wang and L. Wang, "Dynamics investigation of spatial parallel mechanism considering rod flexibility and spherical joint clearance," Mechanism and Machine Theory, vol. 137, pp. 83-107, 2019.

[10] E. Askari and P. Flores, "Coupling multi-body dynamics and fluid dynamics to model lubricated spherical joints," Archive of Applied Mechanics, vol. 90, pp. 2091-2111, 2020.

[11] W. Xiang and S. Yan, "Dynamic analysis of space robot manipulator considering clearance joint and parameter uncertainty: Modeling, analysis and quantification," Acta Astronautica, vol. 169, pp. 158-169, 2020.

[12] W. Xiang, S. Yan, J. Wu, and W. Niu, "Dynamic response and sensitivity analysis for mechanical systems with clearance joints and parameter uncertainties using Chebyshev polynomials method," Mechanical Systems and Signal Processing, vol. 138, p. 106596, 2020.

[13] Q. Xiao, S. Liu, A. Nie, S. Xiao, and S. Cheng, "Dynamic analysis of the moving mechanism of the reciprocating compressor with clearance joints," Vibroengineering PROCEDIA, vol. 19, pp. 76-81, 2018.

[14] E. Zheng, R. Zhu, S. Zhu, and X. Lu, "A study on dynamics of flexible multi-link mechanism including joints with clearance and lubrication for ultra-precision presses," Nonlinear Dynamics, vol. 83, pp. 137-159, 2015.

\section{PHÂN TÍCH ĐộnG LỰC HỌC CỨNG VÀ ĐÀN HỒI CỦA CƠ CÁU TAY QUAY CON TRƯợT KHÔNG GIAN DỰA TRÊN PHƯƠNG PHÁP PAHANF TỬ HỨU HẠN}

Tóm tắt. Nghiên cứu này phân tích ảnh hưởng của kích thước khoảng hở của khớp bản lề trụ và khớp cầu đến động lực học tuyệt đối cứng-đàn hồi của cơ cấu tay quay con trượt không gian bằng phương pháp phần tử hữu hạn. Mô hình cơ cấu được thiết kế bằng phần mềm Solidworks và sau đó vận tốc, gia tốc, chuyển vị ứng suất và lực tiếp xúc được xác định bằng phương pháp phần tử hữu hạn cúa Rigid-Transient dynamic trong ANSYS. Kết quả mô phỏng chỉ ra rằng thước khoản hở trong khớp bản lề trụ và khớp cầu có ảnh hưởng nhẹ đến vận tốc của con trượt, nhưng ảnh hưởng mạnh đến gia tốc, lực tiếp xúc khi Journal và ball tác động vào bearing và socket với những đỉnh cao của gia tốc và lực tiếp xúc như được trình bày trong đồ thị về gia tốc và lực tiếp xúc. Trong đồ thị này chỉ ra rằng chuyển động của Journal và ball với ba kiểu chuyển động: chuyển động tự do, tiếp xúc và tác động. Kích thước khoản hở gây ra sai số chuyển vị của con trượt từ $4.29 \mathrm{~mm}$ đến $9.87 \mathrm{~mm}$ và ứng suất chính cực đại gia tăng từ $8.4 \mathrm{MPa}$ đến $10 \mathrm{MPa}$ khi kích thuớc khoản hở tăng tử 0 đến $0.3 \mathrm{~mm}$.

Từ khóa: Cơ cấu tay quay con trượt không gian, Phương pháp phần tử hữu hạn, Động lực học tuyệt đối cứng-đàn hồi, khớp bản lề trụ có khoản hở, khớp cầu có khoản hở.

Ngày nhận bài: 22/04/2021

Ngày chấp nhận đăng:30/06/2021 